\title{
Immunocytochemical Localization of HrpA and HrpZ Supports a Role for the Hrp Pilus in the Transfer of Effector Proteins from Pseudomonas syringae pv. tomato Across the Host Plant Cell Wall
}

\author{
Ian R. Brown, ${ }^{1}$ John W. Mansfield, ${ }^{1}$ Suvi Taira, ${ }^{2}$ Elina Roine, ${ }^{2}$ and Martin Romantschuk ${ }^{2}$ \\ ${ }^{1}$ Department of Biological Sciences, Imperial College at Wye, University of London, Ashford, Kent, TN25 \\ 5AH, U.K.; ${ }^{2}$ Biocenter Viikki, Department of Biosciences, Division of General Microbiology, P. O. Box 56 \\ (Viikinkaari 9C), FIN-00014 University of Helsinki, Finland \\ Accepted 12 October 2000.
}

\begin{abstract}
The Hrp pilus, composed of HrpA subunits, is an essential component of the type III secretion system in Pseudomonas syringae. We used electron microscopy (EM) and immunocytochemistry to examine production of the pilus in vitro from $P$. syringae pv. tomato strain $\mathrm{DC} 3000$ grown under $h r p$-inducing conditions on EM grids. Pili, when labeled with antibodies to $\mathrm{HrpA}$, developed rapidly in a nonpolar manner shortly after the detection of the hrpA transcript and extended up to $5 \mu \mathrm{m}$ into surrounding media. Structures at the base of the pilus were clearly differentiated from the basal bodies of flagella. The HrpZ protein, also secreted via the type III system, was found by immunogold labeling to be associated with the pilus in vitro. Accumulation and secretion of $\operatorname{HrpA}$ and $\operatorname{HrpZ}$ were also examined quantitatively after the inoculation of wild-type DC3000 and $h r p A$ and $h r p Z$ mutants into leaves of Arabidopsis thaliana. The functional pilus crossed the plant cell wall to generate tracks of immunogold labeling for HrpA and HrpZ. Mutants that produced HrpA but did not assemble pili were nonpathogenic, did not secrete HrpA protein, and were compromised for the accumulation of HrpZ. A model is proposed in which the rapidly elongating Hrp pilus acts as a moving conveyor, facilitating transfer of effector proteins from bacteria to the plant cytoplasm across the formidable barrier of the plant cell wall.
\end{abstract}

Type III secretion systems are recognized to have essential roles in the virulence of several bacterial pathogens of plants, animals, and humans (Galan and Collmer 1999; Hueck 1998). Certain proteins forming the structural architecture of the export apparatus are conserved among gram-negative genera and appear to have evolved by duplication of the flagellar gene cluster and specialization into what has been described as an "injection organelle" (He 1997). The secretory apparatus has been identified to form "needle complexes" and "secretons," which are visible under the electron microscope (EM) in Sal-

Corresponding author: J. Mansfield; Telephone: +44 1233812401; Fax: +44 1233813140; E-mail: j.mansfield@ic.ac.uk monella and Shigella spp., respectively (Blocker et al. 1999; Kimborough and Miller 2000; Kubori et al. 1998; Kubori et al. 2000). In plant pathogenic bacteria, the type III secretion apparatus is encoded by hrp genes that are clustered into a pathogenicity island on the chromosome of Erwinia, Pseudomonas, and Xanthomonas spp. and on a megaplasmid in Ralstonia solanacearum (Lindgren 1997; Van Gijsegem 1997). Certain $h r p$ genes encode proteins that are conserved among plant and animal pathogens and have been renamed $h r c$ (for hrp gene conserved) by Bogdanove et al. (1996). Eight of the nine hrc genes in Pseudomonas spp. have significant sequence similarity to genes involved in the assembly of the flagellar basal body (He 1997). Mutation in hrp genes leads to pleiotropic loss of pathogenicity and the ability to elicit the hypersensitive reaction (HR) in resistant plants (either host cultivars or nonhosts). The Hrp minus phenotype is thought to be as result of the failure of mutants to deliver proteinaceous effectors (the products of vir and $a v r$ genes) to the plant cell cytoplasm (Alfano and Collmer 1997; Grant and Mansfield 1999; Jackson et al. 1999; Mudgett and Staskawicz 1998; Tsiamis et al. 2000).

Pathogens of animals come into direct contact with their host's cell membrane. The type III secretion systems appear to facilitate the subsequent polarized transfer of virulence proteins into the animal cell cytoplasm (Galan and Collmer 1999; Hartland et al. 2000; Rosqvist et al. 1995). In plants, the cellulosic cell wall presents a formidable barrier to the transfer of such factors between the prokaryote and eukaryote cells. The protein product of the hrpA gene from the Arabidopsis and tomato pathogen $P$. syringae pv. tomato strain DC3000 was shown to autoassemble into an extracellular pilus that develops on bacteria grown in minimal media that induced hrp gene expression (Roine et al. 1997a; Roine et al. 1997b). Mutational analysis of $h r p A$ has indicated that the carboxy-terminus of the HrpA subunit is required for pilus assembly (Taira et al. 1999). Additional proteins secreted by DC3000 and other pathovars of $P$. syringae under inducing conditions are the harpins, HrpZ and HrpW, which act as elicitors of the HR in tobacco and tomato. Other effectors such as the avr gene products AvrB and AvrPto are exported much less readily (Alfano et al. 1996; Charkowski et al. 1998; Grant and 
Mansfield 1999; Preston et al. 1995). The hrpA and hrpZ genes are components of an operon in DC3000, which also encodes $h r p B$, $h r c J, h r p D$, and $h r p E$ (Preston et al. 1995). Hrp pili have been reported to reach up to $2 \mu \mathrm{m}$ in length and, therefore, have the potential to cross plant cell walls. As a result, the pilus may act as a conduit for protein delivery (He 1997; Roine et al. 1997a; Roine et al. 1997b). Hrp pili composed of HrpY subunits have been described in $R$. solanacearum, the cause of bacterial wilt of tomato (Van Gijsegem et al. 2000). Similarly, the formation of an elongated pilus has also been associated with the delivery of the T-DNA-protein complex across the plant cell wall by the crown gall bacterium, Agrobacterium tumefaciens (Fullner et al. 1996). In Agrobacterium spp., however, the secretion apparatus including the pilus is characteristic of a type IV rather than a type III system (Finlay and Falkow 1997; Lai and Kado 2000; Stein et al. 2000).

We used immunocytochemistry to examine the development of the Hrp pilus by $P$. syringae pv. tomato in vitro and in the plant as well as the relationship between HrpA and other secreted proteins. Immunocytochemical localization of HrpA and HrpZ in wild-type and mutant strains of DC3000 by electron microscopy (EM) revealed that HrpZ and HrpA are secreted from the same sites in the bacterial outer membrane, the Hrp pilus crosses the plant cell wall, and HrpZ is closely associated with the pilus. A model in which the rapidly elongating pilus acts as a moving conveyor, facilitating transfer of proteins between bacterial and plant cytoplasm, has been proposed.

\section{RESULTS}

\section{Development of pili in vitro.}

The Hrp pilus has been identified previously from preparations of bacteria recovered from agar or liquid culture (Roine et al. 1997b). A major problem with both methods is the fragmentation of the delicate pili and their detachment from bacterial cells before examination. In order to examine pilus development more accurately, we devised a system of growing bacteria in droplets of hrp-inducing medium on coated grids used for transmission EM. Samples were fixed in situ on grids to preserve surface structures by nondestructive immersion into a droplet of concentrated fixative. Preliminary observations after incubation of samples for 1, 2, and 3 days revealed the production of numerous Hrp pili, up to $5 \mu \mathrm{m}$ in length and 6 to $8 \mathrm{~nm}$ in diameter, which were clearly differentiated from flagella (Fig. 1A). The Hrp pili labeled strongly with antiserum raised to the reassembled HrpA protein and often appeared bundled in groups of two or three filaments (Fig. 1B and C). No labeled pili were produced by the nonpolar $h r p A$ mutant (DC3000 4 hrpA::apf), but other surface structures were evident (Fig. 1D).

Although extended pili were clearly visible in vitro, their organization at the bacterial surface was often obscured by the production of extracellular polysaccharides, the accumulation of counterstain around bacterial cells, and the fact that pili emerged from both the upper and lower faces of the bacteria and the equatorial region. Nevertheless, successful tracking of pili labeled with HrpA antiserum led back to basal structures (Fig. 2A). The basal bodies of flagella were often released during preparation for EM (Fig. 2B). By contrast, no struc- tures were released from the base of the more numerous Hrp pili, even if cells were ruptured by osmotic shock and detergent treatments (data not shown).

Time-course studies showed that pili had developed after $1 \mathrm{~h}$ incubation in vitro. Even at the early time points, very few short pili were observed. Once they had emerged from the cell, they extended extremely rapidly (Fig. 3). The numbers of pili produced increased with time and there was no indication of synchronous development from different sites or any polarity to their location in DC3000. The apparently random distribution contrasted with the polar production of Hrp pili in $R$. solanacearum (Van Gijsegem et al. 2000).

\section{Expression of $h r p A$ in vitro.}

Northern blots were prepared to examine the time course of hrpA expression in the medium used to observe pilus extension. Levels of $h r p A$ mRNA had increased significantly by 30 min after inoculation into $h r p$-inducing media before pili were first observed. A low level of constitutive expression was detected in bacteria grown in rich media prior to transfer to established inducing conditions (Fig. 4).

\section{Labeling with anti-Hrp $\mathrm{Z}$ antiserum in vitro.}

Pili that developed from bacteria grown on grids for $12 \mathrm{~h}$ or more were not labeled in an obvious manner by anti-HrpZ antibodies, although the HrpZ protein was detected in the extracellular milieu (Fig. 3A). During the earlier stages of development, however, the Hrp pili produced were associated with a characteristic pattern of immunogold labeling for HrpZ, as illustrated in Figures $3 \mathrm{~B}$ to E. The label often appeared most dense at the base of the pili and reduced away from the bacterial cell to give, in some cases, an elongated, pyramidlike distribution (Fig. 3B and C). The association of HrpZ with HrpA pili was confirmed by dual labeling with a mixture of antisera raised in rabbits or mice, respectively, and labeled with different sizes of gold particle (Fig. 3D and E). The frequency of labeling reduced with time so that after $12 \mathrm{~h}$ of incubation, very few pili were heavily decorated by the antiHrpZ antibody. The patterns of colocalization of HrpZ and HrpA observed indicated secretion from the same site in the bacterial membrane. Immunogold labeling of HrpZ was often associated with an electron dense amorphous matrix, which appeared to surround the Hrp pilus during the first $6 \mathrm{~h}$ of growth on grids (Fig. 3B and C).

\section{Pilus and HrpZ production by $h r p A$ and $h r p Z$ mutants in vitro.}

A selection of the hrpA insertion mutants described by Taira et al. (1999) was examined. The strains used express mutagenized $h r p A$ from the plasmid pDN18-N as transconjugants in a $h r p A^{-}$background. The patterns of immunogold labeling for HrpA were as predicted from the properties of each strain. Thus mutants 254 and 246, which accumulate a form of HrpA but do not assemble the Hrp pilus in vitro, were effectively unlabeled, apart from the presence of randomly distributed sparse gold label at the surface of 254. By contrast, insertions 167 and 298 (located in the N and C termini of HrpA, respectively) still produce functional pili and had the same distribution of anti-HrpA label as wild-type DC3000 (Fig. 5A).

Labeling of the hrpA mutants with antibodies to HrpZ was also examined. No gold label accumulated outside cells of the 
noncomplemented $h r p A$ nonpolar mutant after labeling with HrpZ antiserum, a result consistent with the proposed regulatory role of HrpA (Wei et al. 2000). Very low levels of HrpZ label were also observed around the functional Hrp pili in mutants 167 or 298 (Fig. 5B), indicating the failure of $h r p A$ provided in trans to complement the effects of the $h r p A$ mutation on hrpZ. The numbers of gold particles around cells of the other mutants, 246 and 254, were only marginally greater than the background labeling observed with the hrpZ mutant CUCPB5094 (Fig. 5C to F).

\section{Development of the Hrp pilus in the plant.}

HrpA and HrpZ were localized within leaves of Arabidopsis thaliana ecotype Columbia inoculated with DC3000 strains. Following inoculation of bacterial suspensions, the water droplets surrounding bacteria became absorbed or evaporated, bacterial cells were deposited on plant cell walls, particularly at cell junctions (Bestwick et al. 1998). The plant was susceptible to colonization by wild-type bacteria and the insertion mutant transconjugants 167 and 298, which produce pili. During the susceptible response, bacteria multiplied within the intercellular spaces causing tissue collapse 1 to 2 days after inoculation. The $h r p A$ mutants 246 and 254 failed to cause any symptoms and did not multiply at sites of infiltration.

Immunogold labeling of $\mathrm{HrpA}$ was observed within and around wild-type bacteria $1 \mathrm{~h}$ after inoculation. The frequency of label increased with time, but was never dense. At most, 12 gold particles were observed within a section of a bacterial cell. The label was often associated with bacterial membranes and outside bacteria within the bacterial colony. Labeling also extended into the plant cell wall and, to a much lesser extent, into the peripheral cytoplasm. At some sites, lines of gold particles were seen to cross the plant cell wall adjacent to bacteria, indicating penetration by the Hrp pilus (Fig. 6A to C). Similar patterns of labeling were observed with the pathogenic insertion mutants 167 and 298 (Fig. 6D). By contrast, the label was restricted to the bacterial cell in mutants 246 and 254, both of which produce a mutant form of HrpA protein but fail to assemble pili (Fig. 6E). The background level of labeling was negligible around the $h r p A$ mutant DC3000 $h$ rpA::apf (not shown).

A quantitative analysis of immunogold labeling was completed for wild-type DC3000 and hrpA mutants to provide an
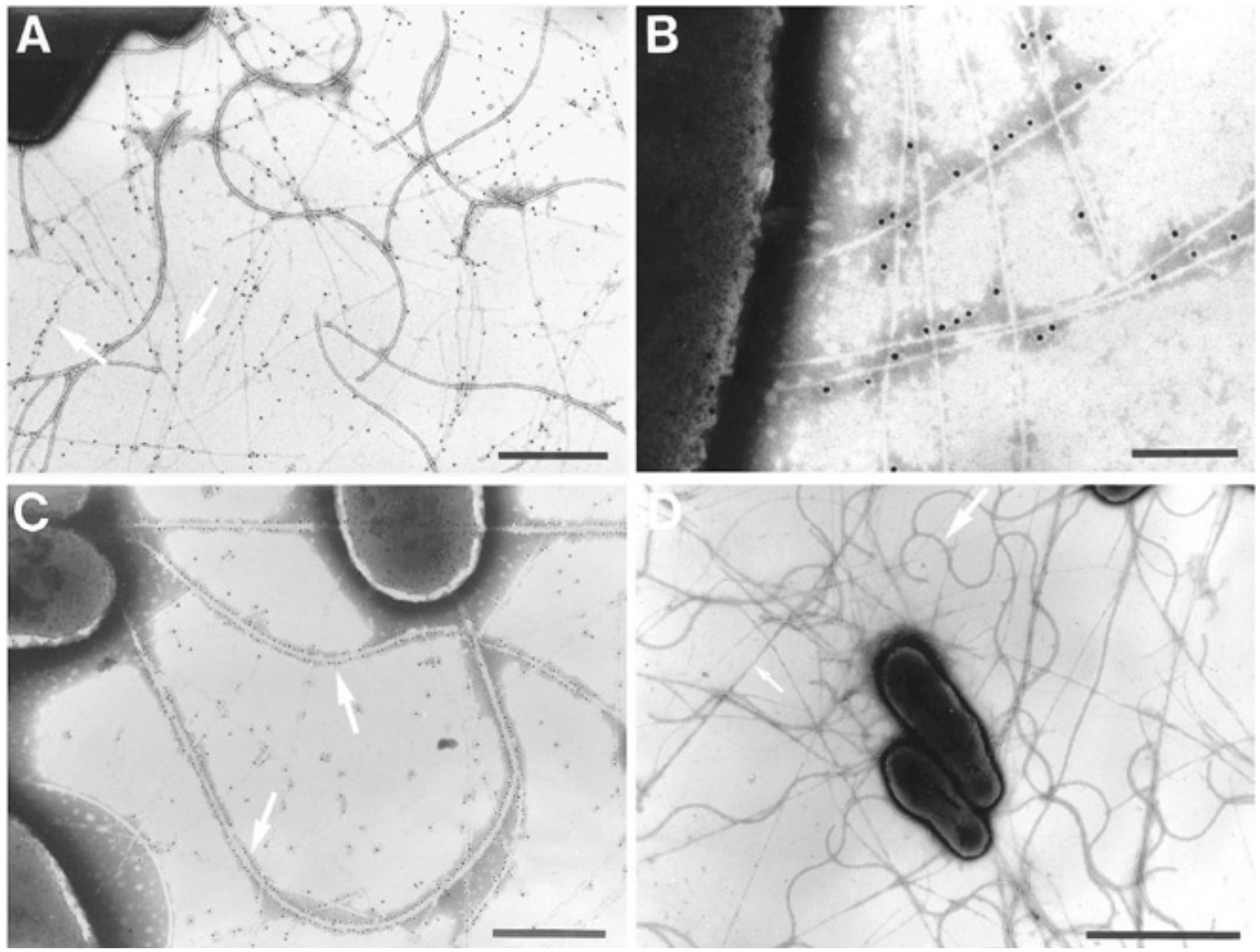

Fig. 1. Production of pili and flagella by bacteria grown on electron microscopy grids in minimal ( $h r p$-inducing) medium. All specimens were immunogold labeled to detect the HrpA protein A, 3 days after inoculation and $\mathbf{B}$ to $\mathbf{D}$, after 1 day. A, Wild-type DC3000 produce long pili that are decorated with immunogold label (arrows). Bar $=1 \mu \mathrm{m}$. B, Immunogold labeling of individual Hrp pili. Note that gold label settles alongside the filaments. Bar $=$ $0.25 \mu \mathrm{m}$. C, Aggregates of Hrp pili comprising two or three individual filaments (arrows) are strongly labeled. Bar $=0.5 \mu \mathrm{m}$. D, The nonpolar $h r p A$ mutant produces flagella (large arrow) and straight pilus-like structures (small arrow), but these structures are not labeled by HrpA antibodies. $\operatorname{Bar}=2 \mu \mathrm{m}$. 
objective assessment of the distribution of HrpA within and around bacteria and within plant cells. Data presented in Figure 7 confirm qualitative observations that HrpA accumulated within bacterial cells and that the pilus penetrated significantly into the plant cell wall. For example, analysis of combined data for the occurrence of gold label in the plant cell wall 2,3 , and $4 \mathrm{~h}$ after inoculation showed differences between strains producing functional pili (i.e., wild-type and insertion mutants 167 and 298) or no pili (i.e., the hrpA nonpolar mutant and insertions 246 and 254) to be significant at $P$ $<0.01,0.001$, and 0.001 respectively ( $t$ tests). Labeling in the intercellular space was significantly different between the groups of strains at $P<0.001$ at 2,3 , and $4 \mathrm{~h}$ after inoculation. Mutants 167, 254, and 298 accumulated higher levels of HrpA within bacterial cells than did the wild-type DC3000, which expresses $h r p A$ from a single chromosomal copy. Mutant 298 was associated with particularly high levels of HrpA protein labeling, even at $1 \mathrm{~h}$ after inoculation (Fig. 7).

\section{Association of HrpZ with HrpA in the plant.}

In view of the colocalization of HrpA and HrpZ observed in bacteria growing in vitro, the accumulation and distribution of HrpZ in the plant was also examined and quantified (Figs. 6F and 8 ). The frequency of gold label was much greater with antiserum to HrpZ than to HrpA in wild-type cells of DC3000. Most label was found within the bacterial cytoplasm, but there were significant clusters of label associated with the inner and outer membranes. Labeling extended to the intercellular space, to a lesser extent into the plant cell wall and infrequently to the cytoplasm. As observed with HrpA, lines of gold label were occasionally detected within the plant cell wall (Fig. 6F). The nonpolar hrpA mutant accumulated low levels of HrpZ protein within bacteria and the surrounding apoplast (Fig. 8), confirming results obtained in vitro.

\section{DISCUSSION}

\section{Crossing the wall.}

Electron microscopy of plant-bacterium interactions, when combined with immunocytochemistry, has provided valuable information on bacterial multiplication and the localized responses of plant cells to microbial challenge (Bestwick et al. 1997; Bestwick et al. 1998; Brown et al. 1993; Brown et al. 1995). Our experiments have extended the ultrastructural approach to analysis of the delivery of effector proteins from bacteria to plant cells. The quantitative analysis by immunocytochemistry of the distribution of HrpA in planta has confirmed that the Hrp pilus extends into, and probably crosses, the plant cell wall. This conclusion was supported by the comparative analysis of wild-type DC3000 and mutants such as 246 and 254, which accumulated forms of the HrpA protein but were unable to assemble pili. It is important to recognize the inherent difficulty in the immunogold labeling of pili in sections, a problem that may explain the low frequency of occurrence of tracks of label in planta outside bacteria and, in particular, within the plant cell wall. Embedded material, i.e., the pilus, would only be exposed to antiserum at the cut surface (Bestwick et al. 1998). Therefore, the occasional lines or tracks of labeling for HrpA within the plant cell wall must represent areas where a comparatively long stretch of pilus filament has been exposed to the primary antibody. If the pilus extended further into the plant cell, similar tracks might have been expected within the cytoplasm, but none was observed. The HrpA pilus may, therefore, be dissolved into the plant cell membrane or ruptured by cytoplasmic streaming in the peripheral cytoplasm.

\section{Pilus assembly.}

Growth of bacteria on EM grids allowed improved preservation of Hrp pili and other surface structures. The striking speed of development of pili that labeled with antiserum to HrpA indicates the rapid assembly and movement of the pilus into the surrounding milieu. The Hrp pilus was the first appendage to develop in $h r p$-inducing media and, as it emerged, was always associated with a coating of HrpZ. The assembly of the pilus closely followed increases in $h r p A$ and $h r p Z$ transcripts, indicating rapid coordinated synthesis of HrpA and the assembly and export of HrpZ and the Hrp pilus from the type III secretion system. Individual filaments tended to bundle together, a response that may cause the autoagglutination that
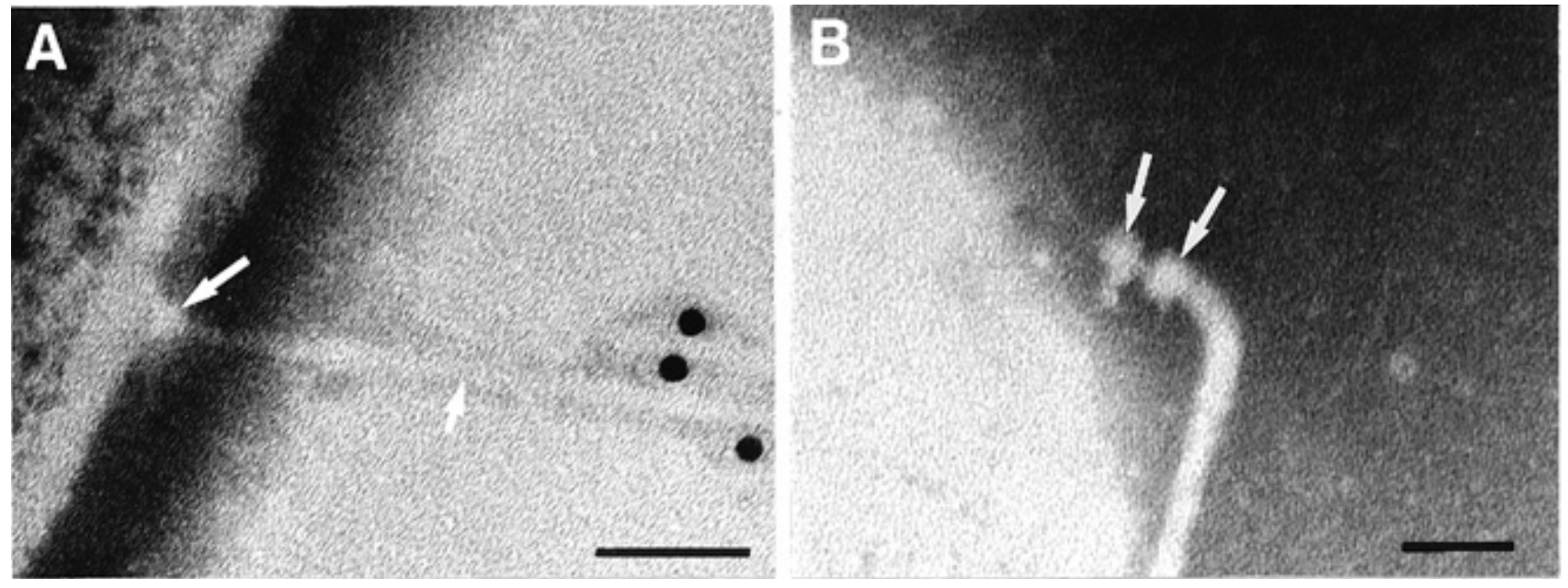

Fig. 2. Basal structures in DC3000 grown on electron microscopy grids under $h r p$-inducing conditions. Bars $=50 \mathrm{~nm}$. A, Structure (large arrow) at the base of a $h r p$-induced pilus (small arrow), immunogold labeled with HrpA antiserum (10-nm particle) away from the bacterial surface. B, Flagellum; note the distinct inner and outer membrane rings (arrows at the base of the hook). 
has been associated with pilus production by DC3000 (Taira et al. 1999). hrpA mutants that failed to assemble pili were unable to colonize Arabidopsis spp.

Membrane-associated structures were observed at the base of Hrp pili, but their resolution was poor and, unlike flagellar basal bodies, they were not released easily into surrounding media. Additional work is necessary to determine whether the plant pathogens form supramolecular needle complexes or secretons composed of type III secretion components, as found in Salmonella and Shigella spp., respectively (Blocker et al. 1999; Kimborough and Miller 2000; Kubori et al. 1998; Kubori et al. 2000). Further examination of the basal structures in DC3000 by immunocytochemistry should allow the location of key components such as the inner and outer membrane $\mathrm{HrcU}$ and $\mathrm{HrcC}$ proteins, respectively, to be determined (Alfano and Collmer 1997; Charkowski et al. 1997).

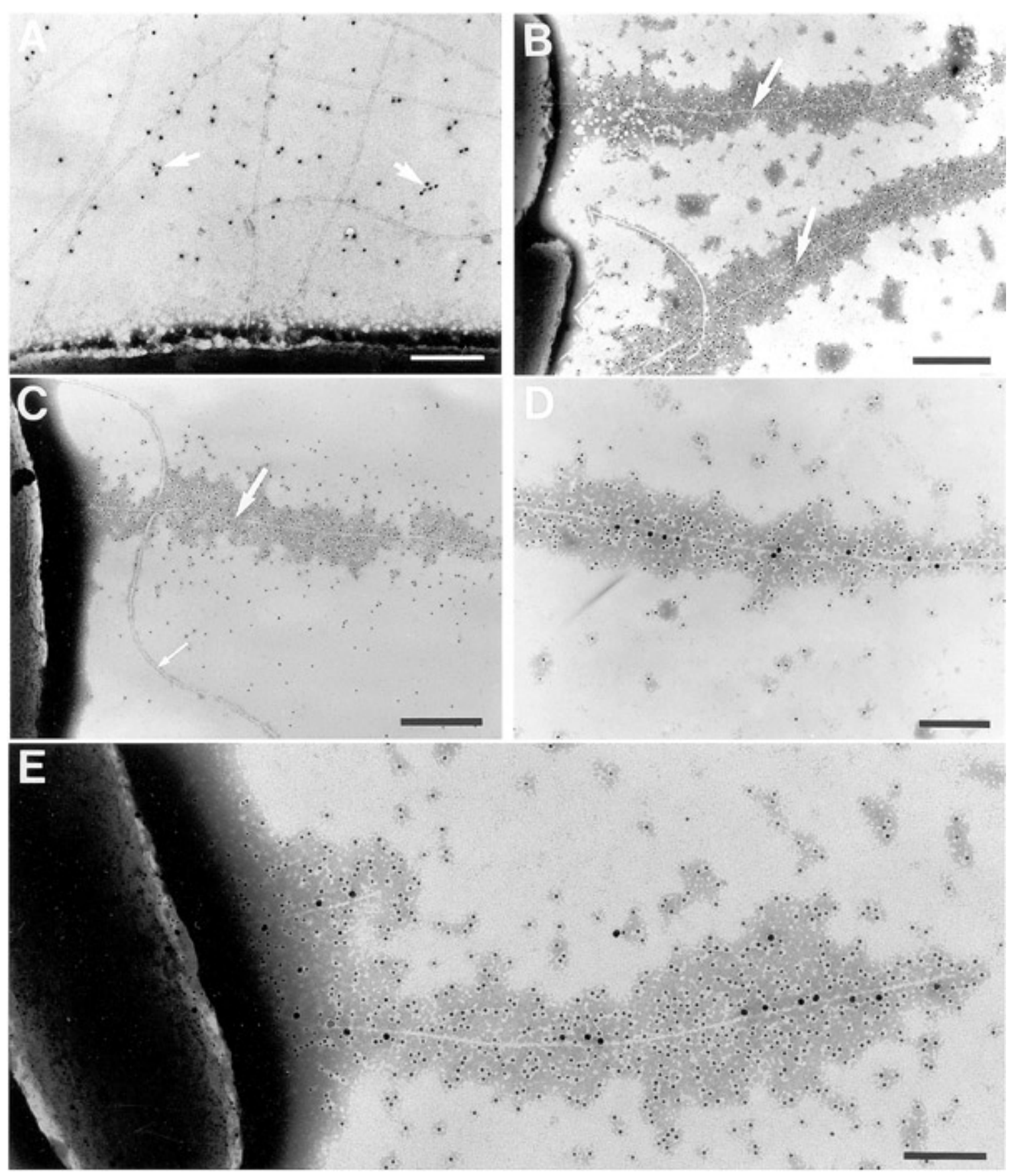

Fig. 3. Immunogold localization of HrpA and HrpZ in wild-type DC3000 grown on electron microscopy grids in minimal (hrp-inducing) medium. A, After incubation for $12 \mathrm{~h}$ immunogold labeling for HrpZ. Arrows indicate dispersal of the protein into the surrounding medium and no obvious association with Hrp pili. Bar $=0.25 \mu \mathrm{m}$. B and C, Specimens immunogold labeled for HrpZ after 3 and $5 \mathrm{~h}$ incubation. Infrequent and comparatively short pili are associated with dense labeling of HrpZ (large arrows), whereas flagella (small arrows) are unlabeled. Bar $=0.5 \mu \mathrm{m}$. D and $\mathbf{E}$, Double labeling with antibodies to HrpZ and HrpA (10- and 20-nm gold label, respectively) confirms the association between HrpZ and the Hrp pilus. Bar $=0.25 \mu \mathrm{m}$. 


\section{Association with HrpZ.}

Distinctive decoration of Hrp pili with HrpZ in vitro was revealed by immunocytochemistry. The HrpZ protein appears to be associated loosely with the pilus. Whether or not the observed interaction is through direct binding between HrpA and HrpZ or involves other linkers is unclear. The involvement of common linkers or chaperones may also facilitate the translocation by the same route of other effectors such as the proteins encoded by avirulence genes. The dispersal of HrpZ from the pilus, with time, is an important observation because it indicates that it is not continuously released from along the filament and may, therefore, only be secreted and accumulate during pilus extension. The presence of electron-dense material containing HrpZ, which appeared to coat the pilus, is intriguing. The matrix may represent secreted proteins stabilized by the macromolecular complex created by the HrpZ component and the anti-HrpZ antibody. Harpin, encoded by $h r p N$ in Erwinia amylovora, has also been located in planta by EM, but any link with the Hrp pilus produced by the fireblight pathogen was not examined (Perino et al. 1999).

In elegant experiments that overcame problems of interpretation brought about by the finding that $h r p A$ may have a regulatory as well as structural role, Wei et al. (2000) demonstrated that protein secretion through the type III system in DC3000 requires the presence of the Hrp pilus and that secretion of HrpA and $\mathrm{HrpW}$ also requires $\mathrm{HrcC}$. Immunocytochemical analysis of HrpZ accumulation and secretion in $h r p A$ mutants grown on grids and in planta confirmed the reported regulatory effect of HrpA (Wei et al. 2000). hrpA mutants of DC3000, however, were compromised for secretion of HrpZ, even if a functional $h r p A$ gene was provided in trans. The hrpA mutant used was designed to be nonpolar in its effects on the $h r p Z$ operon (Roine et al. 1997b), and we confirmed the accumulation of hrpZ transcript by Northern analysis (data not shown). Our results indicate that translation of hrpZ from the polycistronic operon is affected in some way by the nonpolar insertion into hrpA.

\section{Models.}

The patterns of immunogold labeling observed in vitro and in the plant provide clues to the export route taken by HrpZ and allow development of hypotheses on the role of the Hrp pilus in signal delivery. The available evidence supports the following four parameters that have to be incorporated into any model of pilus function: i) HrpA is required for export of proteins through the type III secretion system in $P$. syringae (Wei et al. 2000), ii) HrpA autoassembles (Roine et al. 1997a), iii) the HrpA pilus crosses the plant cell wall, and iv) the Hrp pilus is associated with HrpZ protein. Three possible models incorporating these facts are 1) secretion of HrpA and HrpZ occurs from a common pore in the outer membrane and by the addition of components to its base, and the extension of the pilus through exported HrpZ generates in vitro the appearance of HrpZ coating the filament (i.e., external loading of a conveyor); 2) there is an association between HrpZ and HrpA before pilus assembly and, as the pilus extends from its base, HrpZ is carried out on its surface into the surrounding medium (internal loading of a conveyor); and 3) HrpZ and other proteins are secreted through a pore in the pilus that extends (either from apical or basal HrpA addition) through the discharged protein to produce the labeling patterns observed (moving fountain).
There was a tendency for HrpZ labeling to be more widespread at the pilus base in vitro (Fig. 3B to E), giving a "pyramid" effect. Because a fairly even coating of HrpZ was observed at some distance from the bacterial surface, the external loading of a conveyor as seen in model 1 seems least likely. The moving fountain option, model 3, is supported by homology with the flagellar system. Structural analysis of the flagellar filament reveals a 3-nm wide axial channel (Morgan et al. 1995). In comparison, the $h r p$ pilus is 6 to $8 \mathrm{~nm}$ in diameter and, if it is helically assembled from HrpA, the central lumen could be approximately $2 \mathrm{~nm}$ in diameter, large enough to accommodate and allow movement of an extended protein, although probably not a folded one. As HrpZ does not contain cysteine, it is unlikely to be tightly folded and, therefore, represents a good candidate for rapid secretion through the pilus. Other effector proteins such as those encoded by avirulence genes, e.g., avrB, avrPphB, avrPphE, avrPto, avrRpml, and avrRpt2, are known to function within plant cells and are expected to be delivered via the pilus (Alfano and Collmer 1997; Bonas and Van den Ackerveken 1997; Gopalan et al. 1996; Leister et al. 1996; Stevens et al. 1998). The Avr proteins, however, all contain numerous cysteine residues and are likely to be folded in their final conformation and unlikely to be transportable within the pilus lumen. Secretion through the pilus, across the cell wall, and from the pilus tip would also require a mechanism to generate directed long-distance protein movement. By contrast, the autoassembly of the pilus, if occurring from the pilus base as proposed in models 1 and 2,

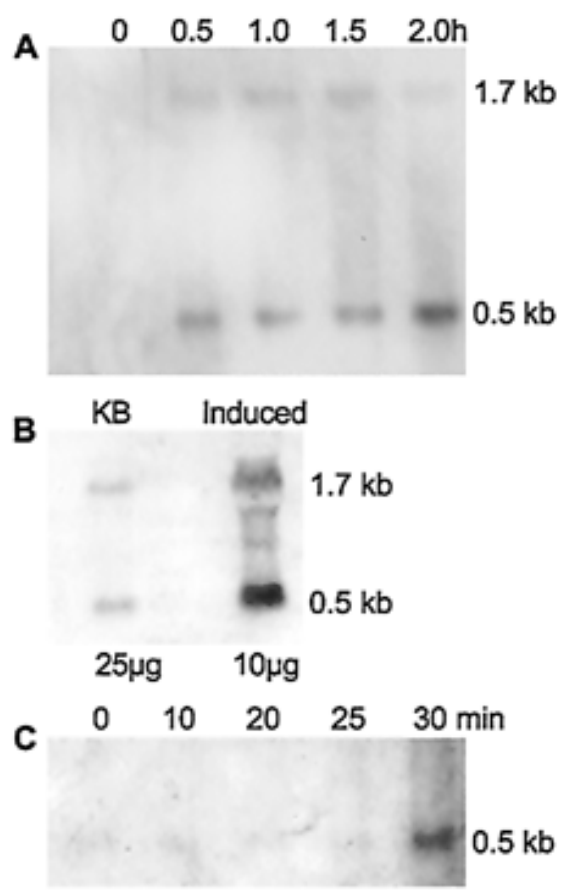

Fig. 4. Analysis of $h r p A$ transcription in bacteria grown under hrpinducing conditions. Northern blots were probed with antisense hrpA. A, Time course showing accumulation of $h r p A$ and $h r p A+h r p Z$ transcripts of 0.5 and $1.7 \mathrm{~kb}$, respectively. Ten micrograms of total RNA were loaded. B, Detection of $h r p A$ and $h r p A+h r p Z$ transcripts in bacteria grown in King's B medium with $25 \mu \mathrm{g}$ RNA loading, compared with accumulation under inducing conditions. Bacteria were incubated for $2 \mathrm{~h}$ in each medium. C, Accumulation of $h r p A$ mRNA minutes after transfer to inducing medium. 
would drive an effective physical conveyor in the form of the extending filament. On balance, internal loading of a conveyor, model 2, would seem most likely. Even with this model, the problem of protein conformation remains. If folded proteins are internally attached to the assembling pilus, the pore in the bacterial membranes must be large enough to accommodate a supramolecular structure that is much wider than the diameter of the pilus alone. Further characterization of the type III architecture and mode of assembly of the pilus should help to validate the model proposed.

It has been suggested that the Hrp pilus may act as an adhesion device rather than a conduit for the translocation of effector proteins (Alfano and Collmer 1997). If the pilus merely anchors bacteria close to the plant cell, then another route must be found across the cell wall for proteins secreted from the bacterial surface. The plant cell wall is a porous hydrophilic matrix through which water movement occurs within the transpiration stream (Newman 1976). Hydrophilic proteins released into the wall are expected to diffuse in the direction of the movement of apoplastic water and not simply traverse directly to the host cell membrane. The enormity of the plant cell wall barrier is illustrated in Figure 6C; the distance across the wall is at least five times that which occurs between the bacterial membranes. Whether or not delivery involves type III or IV secretion, evolution of the elongated pilus may have been a common answer to the questions posed to bacterial pathogens by the plant cell wall barrier.
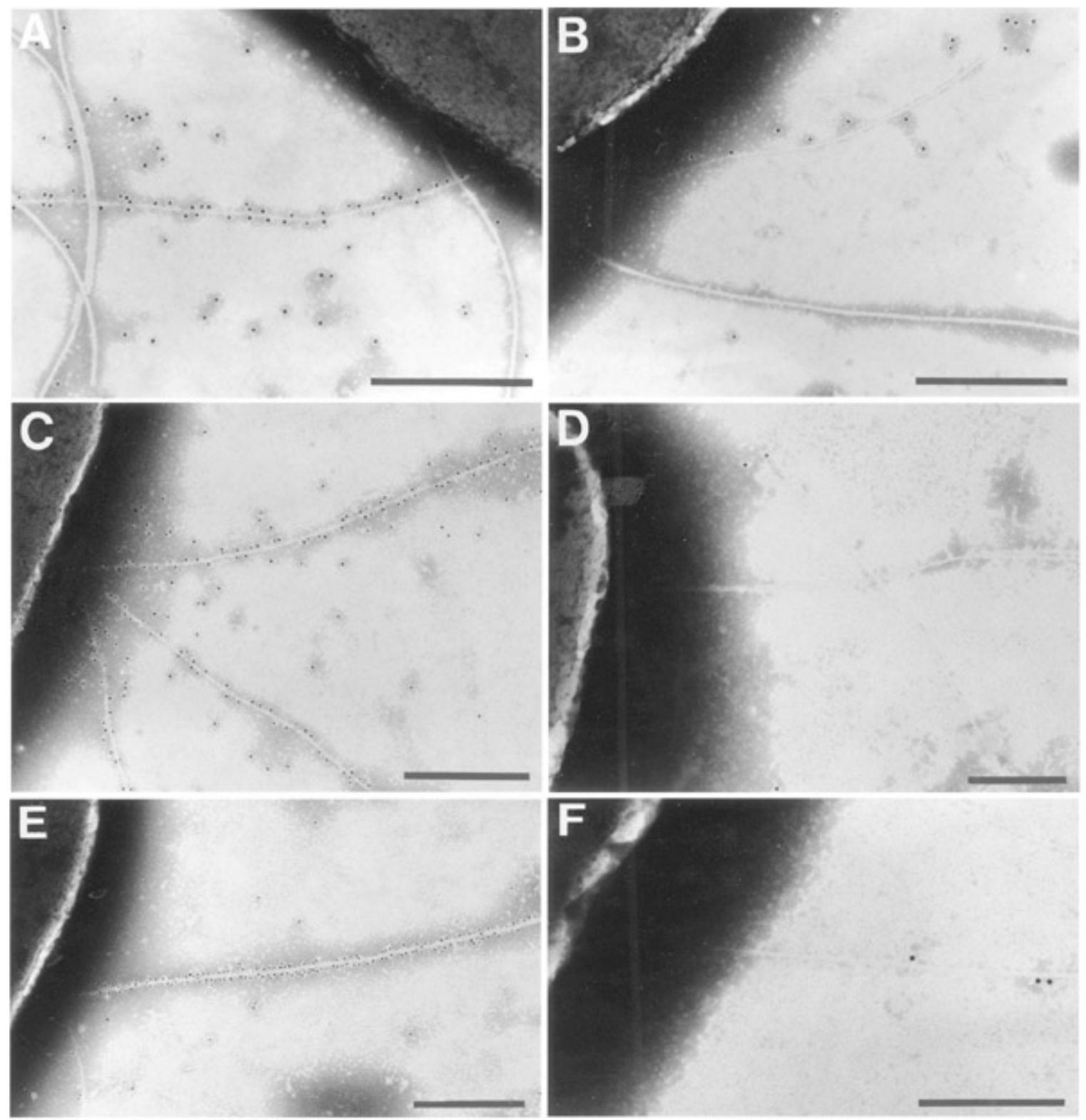

Fig. 5. Immunogold localization of HrpA and HrpZ in hrpA and hrpZ mutants. A and B, Transconjugant of a nonpolar hrpA mutant of DC3000 complemented by pDN18-N, with 167 containing $h r p A$ with a 15-bp insertion yet causing no effect on pilus formation, and incubated for $24 \mathrm{~h}$. A, The typical pattern of labeling for HrpA and $\mathbf{B}$, the greatly reduced level of HrpZ labeling compared with wild type (compare Fig. 3). C to F, hrpZ mutant immunogold-labeled for $\operatorname{HrpA}(\mathbf{C}$ and $\mathbf{E})$ and $\operatorname{HrpZ}(\mathbf{D}$ and $\mathbf{F})$ after incubation in the inducing medium for $6 \mathrm{~h}$. $\mathbf{C}$ and $\mathbf{E}$, Single and bundled pili, respectively. $\mathbf{A}, \mathbf{B}, \mathbf{C}$, and $\mathbf{E}$, Bars $=0.5 \mu \mathrm{m} ; \mathbf{D}$ and $\mathbf{F}$, Bars $=0.25 \mu \mathrm{m}$. 


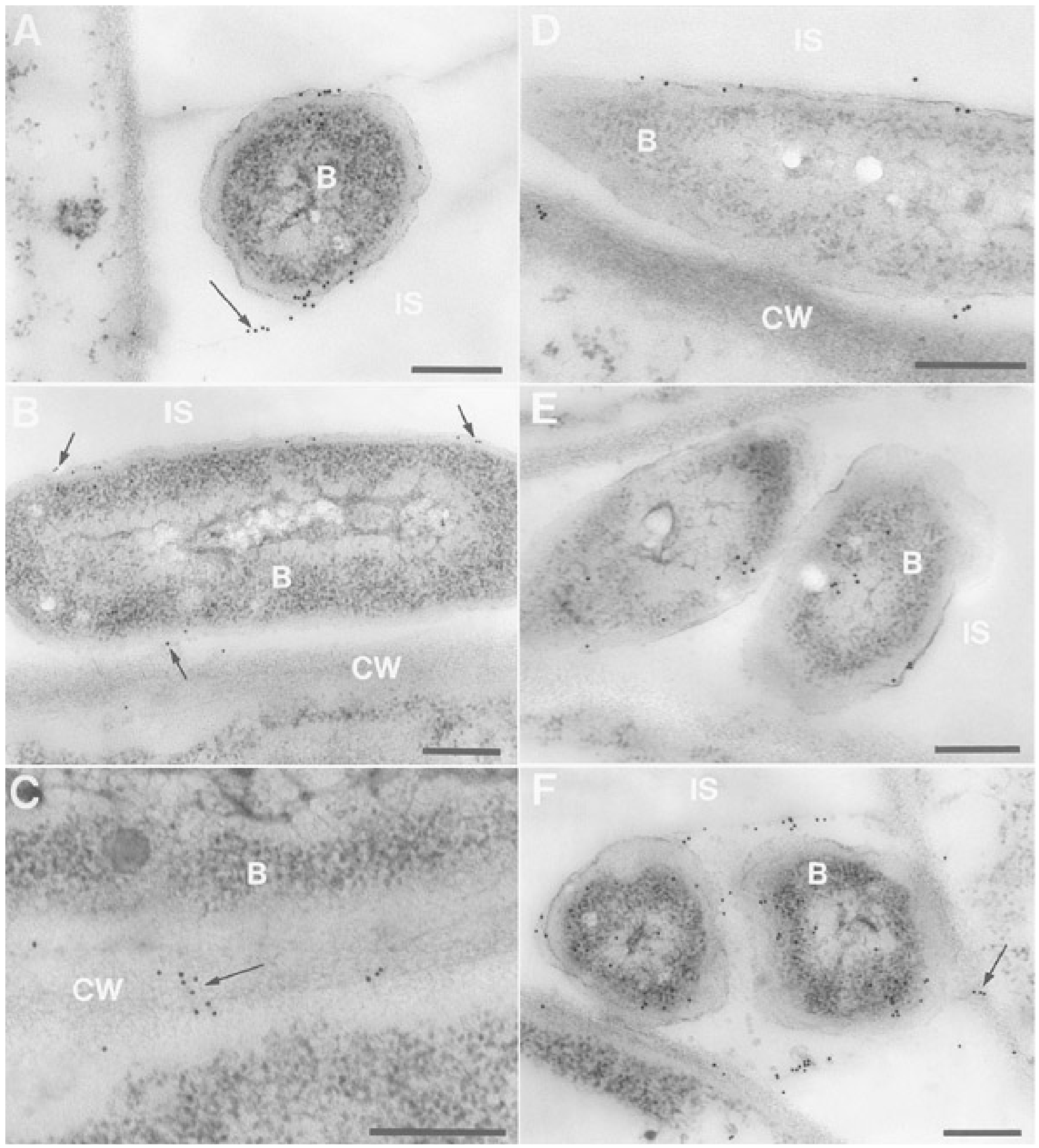

Fig. 6. Immunogold localization of HrpA and HrpZ in transmission electron microscopy sections prepared $3 \mathrm{~h}$ after inoculation of bacteria into Arabidopsis spp. leaves. Bars $=0.25 \mu \mathrm{m}$. A to C, Wild-type DC3000 labeled with HrpA antibodies. A, Note that labeling is dense at the edge of the microcolony (arrow). B, Nonpolar distribution of HrpA at sites within the bacterial membrane is indicated by the presence of label adjacent to the plant cell wall and on the opposite side of the bacterium (arrows). C, Rare "track" of label crossing the plant cell wall (arrow). Labeling within the wall is also apparent in A and B. D, Labeling of HrpA in the insertion mutant 298, which continues to produce Hrp pili. Note gold label within the intercellular space and plant cell wall. E, Labeling of HrpA in the insertion mutant 254, which fails to produce Hrp pili in vitro. Note accumulation of immunogold label within the bacterium. F, Immunogold localization of HrpZ in wild-type DC3000. Note the greater density of labeling than observed with HrpA and the presence of gold label within the bacterial cytoplasm, intercellular space, and as a track within the plant cell wall (arrow). 


\section{MATERIALS AND METHODS}

\section{Plants and bacteria.}

Plants of A. thaliana ecotype Columbia were grown and leaves were inoculated by infiltration of suspensions of $P$. syringae pv. tomato DC3000 (Whalen et al. 1991) by a syringe without a needle (Roine et al. 1997b). The inoculum concentration used was $2 \times 10^{8} \mathrm{CFU} / \mathrm{ml}$ in $1 \mathrm{mM} \mathrm{MgCl}$. The construction of the nonpolar $h r p A$ and $h r p Z$ mutants, $\Delta h r p A:: a p h$ and $\Delta h r p Z:: n p t I I$ (CUCPB5094), has been described previously (Alfano et al. 1996; Roine et al. 1997b). The hrpA insertion mutants 167, 246, 254, and 298 were generated in pDN18-N and assessed in the $\triangle h r p A$ background, as described previously (Taira et al. 1999).

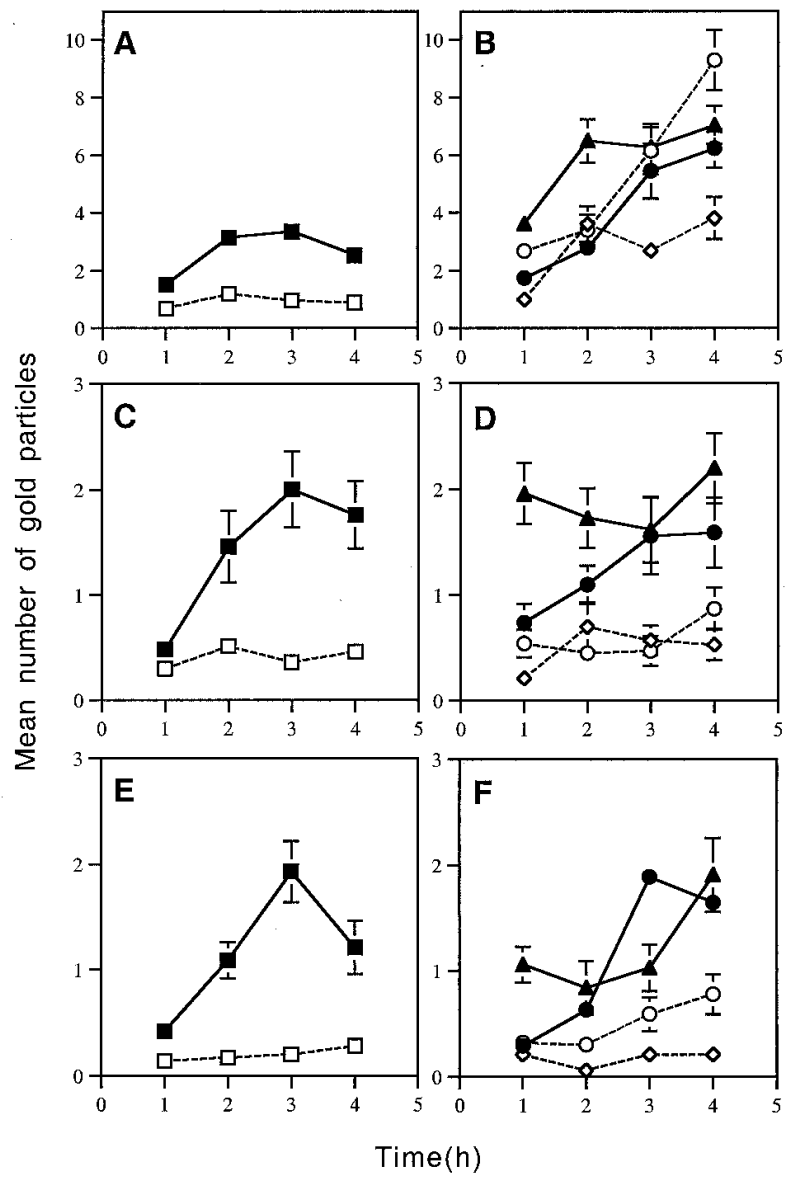

Fig. 7. Quantitative analysis of the presence of immunogold label for HrpA in wild-type DC3000 (घ), nonpolar $h r p A$ mutant ( $\square$ ), and $h r p A$ mutant bacteria, complemented by $h r p A$ with insertions $167(\bullet)$ and 298 $(\boldsymbol{\Lambda})$, which produce Hrp pili in vitro, and $246(\diamond)$ and $254(\circ)$, which do not. Bacteria were inoculated into leaves of Arabidopsis spp. and tissue prepared for transmission electron microscopy 1 to $4 \mathrm{~h}$ after inoculation. A and B, Immunogold label observed in any part of bacterial cells. C and D, Gold label within the intercellular space surrounding bacteria. $\mathbf{E}$ and $\mathbf{F}$, Gold label in the plant cell wall adjacent to the bacterial microcolony. During the time course in planta, sections of colonies usually contained one or two bacteria and there were no apparent differences in the numbers of wild-type or $h r p A$ mutant bacteria at the early stages of infection examined; 20 to 64 microcolonies were examined for the calculation of each mean number of gold particles observed at locations in the plant and in any part of sectioned bacterial cells. Bars = standard errors, unless covered by symbols.

\section{Antibodies.}

Anti-HrpA serum was raised in rabbits and mice to intact pili of $P$. syringae pv. tomato DC3000, as described by Roine et al. (1997b). Polyclonal antibodies were generated to the HrpZ protein from $P$. syringae pv. syringae and $P$. syringae pv. phaseolicola (He et al. 1993). Cross reaction and specificity against HrpZ from $P$. syringae pv. tomato was confirmed by Western blotting. The antiserum against HrpZ from P. syringae pv. phaseolicola was chosen for immunocytochemistry because it gave very little background labeling against the hrpZ mutant or plant tissues (data not shown).

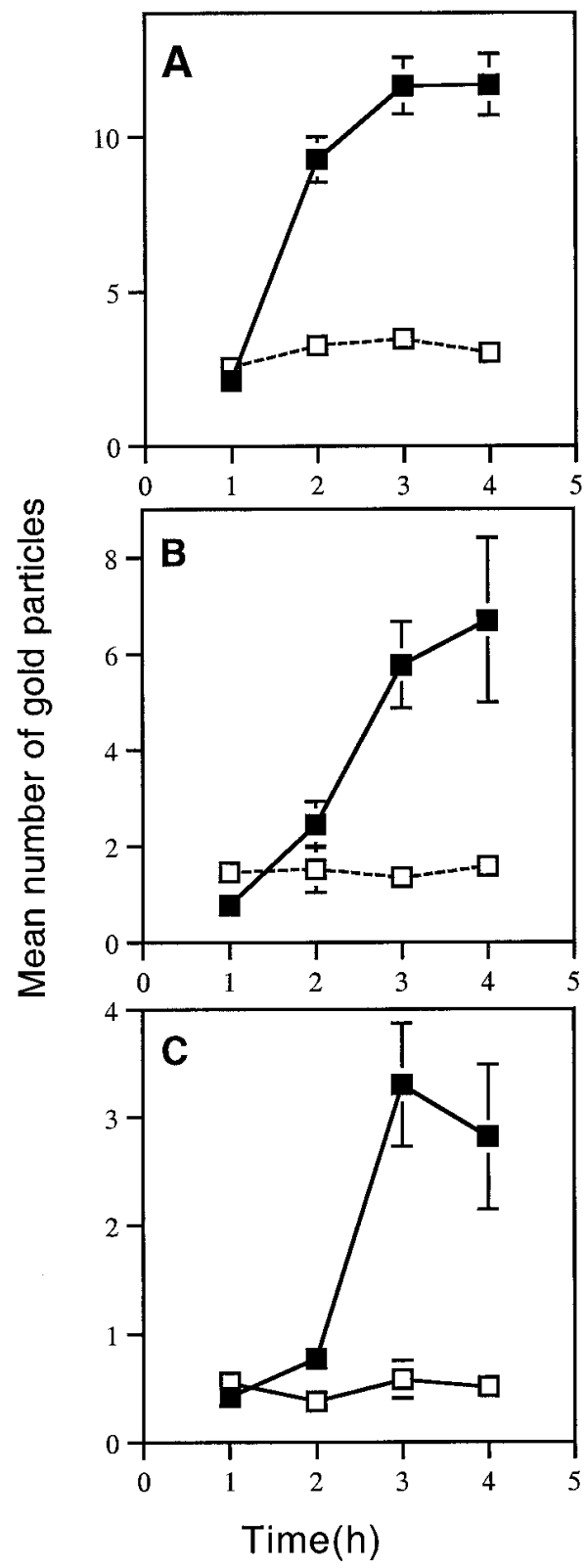

Fig. 8. Quantitative analysis of the presence of immunogold label for HrpZ in wild-type DC3000 (ש) and the nonpolar hrpA mutant ( $\square$ ). A, Immunogold label observed in any part of the bacterial cells. B, Gold label within the intercellular space surrounding bacteria. $\mathbf{C}$, Gold label in the plant cell wall adjacent to the bacterial microcolony; sections examined as in Figure 7. 


\section{Growth of bacteria on grids.}

Bacteria were grown on 300-mesh gold EM grids coated in $2 \%$ Formvar and carbon. The prepared grids were placed on Parafilm stretched over a $5-\mathrm{cm}$ glass square that was positioned in a $9-\mathrm{cm}$ petri dish containing six filter papers. The apparatus was sterilized by exposure to UV (254 nm) overnight. Bacterial cultures were grown overnight in King's B medium (King et al. 1954) with shaking at $28^{\circ} \mathrm{C}$. Bacteria were washed twice by centrifugation and resuspension in $1 \mathrm{mM} \mathrm{MgCl}{ }_{2}$ and resuspended in hrp-inducing minimal medium containing $10 \mathrm{mM}$ fructose (Huynh et al. 1989). The bacterial suspension was adjusted to $10^{8} \mathrm{CFU} / \mathrm{ml}$, and a $20 \mu \mathrm{l}$ droplet was applied to the grid. The filter papers were wetted with sterile distilled water, and the petri dish lid sealed with Parafilm. Grids were incubated in a growth chamber at $21^{\circ} \mathrm{C}$. After a period of incubation, bacteria and pili were fixed by transferring the grid into one $20-\mu \mathrm{l}$ drop, then another immediately afterward containing $2 \%$ formaldehyde and $0.5 \%$ glutaraldehyde in $50 \mathrm{mM}$ sodium cacodylate buffer, $\mathrm{pH} 7.2$, for $30 \mathrm{~min}$. Grids were then washed in a stream of TBST $(20 \mathrm{mM}$ Tris; $500 \mathrm{mM} \mathrm{NaCl} ; 0.1 \%$ bovine serum albumin [BSA]; and $0.05 \%$ Tween 20, $\mathrm{pH}$ 7.2) from a wash bottle for approximately $15 \mathrm{~s}$. Prior to immunogold labeling, specimens were blocked in 2\% BSA in TBST for $30 \mathrm{~min}$ at room temperature.

All primary antibodies were used at a dilution of 1:500, and grids were incubated for $2 \mathrm{~h}$ at room temperature. Goldlabeled second antibodies were $10 \mathrm{~nm}$ of goat anti-rabbit or $20 \mathrm{~nm}$ goat anti-mouse (British Biocell International, Cardiff, U.K.), which were diluted 1:50, and grids were incubated for $1 \mathrm{~h}$ at room temperature. After washing in TBST and distilled water, specimens were negatively stained for $10 \mathrm{~s}$ in $1 \%$ phosphotungstic acid adjusted to $\mathrm{pH} 6.5$ with $\mathrm{KOH}$ and air dried before viewing. In dual labeling of HrpA and HrpZ, HrpA was labeled first with mouse anti-HrpA visualized with $20 \mathrm{~nm}$ gold. Grids were blocked again, and HrpZ was labeled and visualized with $10 \mathrm{~nm}$ gold. Preimmune serum diluted 1:500 and/or omission of primary antibody and incubation in buffer alone was used for negative controls for all antisera.

\section{Electron microscopy and immunogold labeling.}

Preparation, labeling, and staining of inoculated plant material were performed essentially as described previously (Brown et al. 1993), except that $50 \mathrm{mM}$ sodium cacodylate was used as the buffer in all solutions and tissue was fixed in $2 \%$ (wt/vol) formaldehyde and $0.5 \%$ (vol/vol;) glutaraldehyde. All specimens were examined on a H-7000 transmission EM (Hitachi, Mountainview, CA, U.S.A.) with an accelerating voltage of $75 \mathrm{kV}$.

\section{Transcript analysis.}

RNA was isolated by the hot phenol method (Von Gabain et al. 1983). Samples were run in $2 \%$ agarose gels denatured with formalin (Sambrook et al. 1989) and transferred to positively charged nylon membranes (Boehringer Mannheim, Lewes, U.K.). Blots were probed with a digoxigenin (DIG)labeled $h r p A$ antisense probe. The probe was labeled with a polymerase chain reaction (PCR) DIG probe synthesis kit (Boehringer Mannheim) by one directional PCR with a hrpA PCR fragment as template and the reverse oligonucleotide, ATATAGAATTCGGGGTACCTCCTCAAGGTAGCGGCCCCCTC, as the primer. Blots were exposed on X-ray film (Kodak, New Haven, CT, U.S.A.).

\section{ACKNOWLEDGMENTS}

Many thanks to N. Panopoulos, A. Collmer, and S. Y. He for strains, antibodies to HrpZ, and invaluable discussion and to $\mathrm{S}$. Reardon for assistance with electron microscopy. We also acknowledge financial support from the BBSRC, EC framework IV Grant BIO-CT97-2244, and the Academy of Finland.

\section{LITERATURE CITED}

Alfano, J. R., and Collmer, A. 1997. The type III (Hrp) secretion pathway of plant pathogenic bacteria: trafficking harpins, Avr proteins, and death. J. Bacteriol. 179:5655-5662.

Alfano, J. R., Bauer, D. W., Milos, T. M., and Collmer, A. 1996. Analysis of the role of the Pseudomonas syringae pv. syringae HrpZ harpin in elicitation of the hypersensitive response in tobacco using functionally non-polar hrpZ deletion mutations, truncated HrpZ fragments, and hrmA mutations. Mol. Microbiol. 19:715-728.

Bestwick, C. S., Brown, I. R., Bennett, M. H., and Mansfield, J. W. 1997. Localization of hydrogen peroxide accumulation during the hypersensitive reaction of lettuce cells to Pseudomonas syringae pv. phaseolicola. Plant Cell 9:209-221.

Bestwick, C. S., Brown, I. R., Mansfield, J. W., Boher, B., Nicole, M., and Essenberg, M. 1998. Host reactions-plants. Methods Microbiol. 27:539-572.

Blocker, A., Gounon, P., Larquet, E., Niebuhr, K., Cabiaux, V., Parsot, C., and Sansonetti, P. 1999. The tripartite type III secretion of Shigella flexneri inserts $\mathrm{IpaB}$ and IpaC into host membranes. J. Cell Biol. 147:683-693.

Bogdanove, A. J., Beer, S. V., Bonas, U., Boucher, C. A., Collmer, A., Coplin, D. L., Cornelis, G. R., Huang, H. C., Hutcheson, S. W., Panopoulos, N. J., and Van Gijsegem, F. 1996. Unified nomenclature for broadly conserved hrp genes of phytopathogenic bacteria. Mol. Microbiol. 20:681-683.

Bonas, U., and Van den Ackerveken, G. F. J. M. 1997. Recognition of bacterial avirulence proteins occurs inside the plant cell: A general phenomenon in resistance to bacterial diseases? Plant J. 12:1-7.

Brown, I., Mansfield, J., Irlam, I., Conrads-Strauch, J., and Bonas, U. 1993. Ultrastructure of interactions between Xanthomonas campestris pv. vesicatoria and pepper, including immunocytochemical localization of extracellular polysaccharides and the AvrBs3 protein. Mol. Plant-Microbe Interact. 6:376-386.

Brown, I., Mansfield, J., and Bonas, U. 1995. hrp Genes in Xanthomonas campestris pv. vesicatoria determine ability to suppress papilla deposition in pepper mesophyll cells. Mol. Plant-Microbe Interact. 8:825-836

Charkowski, A. O., Huang, H. C., and Collmer, A. 1997. Altered localization of HrpZ in Pseudomonas syringae pv. syringae hrp mutants suggests that different components of the type III secretion pathway control protein translocation across the inner and outer membranes of gram-negative bacteria. J. Bacteriol. 179:3866-3874.

Charkowski, A. O., Alfano, J. R., Preston, G., Yan, J., He, S. Y., and Collmer, A. 1998. The Pseudomonas syringae pv. tomato HrpW protein has domains similar to harpins and pectate lyases and can elicit the plant hypersensitive response and bind to pectate. J. Bacteriol. 180:5211-5217.

Finlay, B. B., and Falkow, S. 1997. Common themes in microbial pathogenicity revisited. Microbiol. Mol. Biol. Rev. 61:136-169.

Fullner, K. J., Lara, J. C., and Nester, E. W. 1996. Pilus assembly by Agrobacterium T-DNA transfer genes. Science 273:1107-1109.

Galan, J .E., and Collmer, A. 1999. Type III secretion machines: Bacterial devices for protein delivery into host cells. Science 284:13221328.

Gopalan, S., Bauer, S. D., Alfano, J. R., Loniello, A. O., He, S. Y., and Collmer, A. 1996. Expression of the Pseudomonas syringae avirulence protein AvrB in plant cells alleviates its dependence on the hypersensitive response and pathogenicity (Hrp) secretion system in eliciting genotype-specific hypersensitive cell death. Plant Cell 8:1095-1105.

Grant, M. R., and Mansfield, J. W. 1999. Early events in host-pathogen interactions. Curr. Opin. Plant Biol. 2:312-319.

Hartland, E. L., Daniell, S. J., Delahay, R. M., Neves, B. C., Wallis, T., Shaw, R. K., Hale, C., Knutton, S., and Frankel, G. 2000. The type III 
protein translocation system of enteropathogenic Escherichia coli involves EspA-EspB protein interactions. Mol. Microbiol. 35:14831492

He, S. Y. 1997. Hrp-controlled interkingdom protein transport: Learning from flagellar assembly? Trends Microbiol. 5:489-495.

He, S. Y., Huang, H.-C., and Collmer, A. 1993. Pseudomonas syringae pv. syringae harpin ${ }_{\text {Pss: }}$ A protein that is secreted via the Hrp pathway and elicits the hypersensitive response in plants. Cell 73:1255-1266.

Hueck, C. J. 1998. Type III protein secretion systems in bacterial pathogens of animals and plants. Microbiol. Mol. Biol. Rev. 62:379-433.

Huynh, T., Dahlbeck, D., and Staskawicz, B. J. 1989. Bacterial blight of soybean: Regulation of a pathogen gene determining host cultivar specificity. Science 245:1374-1377.

Jackson, R. W., Athanassopoulos, E., Tsiamis, G., Mansfield, J. W. Sesma, A., Arnold, D. L., Gibbon, M. J., Murillo, J., Taylor, J. D., and Vivian, A. 1999. Identification of a pathogenicity island, which contains genes for virulence and avirulence, on a large native plasmid in the bean pathogen Pseudomonas syringae pathovar phaseolicola. Proc. Natl. Acad. Sci. USA 96:10875-10880.

Kimborough, T. G., and Miller, S. I. 2000. Contribution of Salmonella typhimurium type III secretion components to needle complex formation. Proc. Natl. Acad. Sci. USA 97:11008-11013.

King, E., Ward, M., and Raney, D. 1954. Two simple media for the demonstration of phycocyanin and fluorescin. J. Lab. Clin. Med. 44:301-307.

Kubori, T., Matsushima, Y., Nakamura, D., Uralil, J., Lara-Tejero, M., Sukhan, A., Galán, J. E., and Aizawa, S.-I. 1998. Supramolecular structure of the Salmonella typhimurium Type III protein secretion system. Science 280:602-605.

Kubori, T., Sukhan, A., Aizawa, S. I., Galán, J. E. 2000. Molecular characterization and assembly of the needle complex of the Salmonella typhimurium type III protein secretion system. Proc. Natl. Acad. Sci. USA 97:10225-10230.

Lai, E.-M., and Kado, C. I. 2000. The T-pilus of Agrobacterium tumefaciens. Trends Microbiol. 8:361-369.

Leister, R. T., Ausubel, F. M., and Katagiri, F. 1996. Molecular recognition of pathogen attack occurs inside of plant cells in plant disease resistance specified by the Arabidopsis genes RPS2 and RPM1. Proc. Natl. Acad. Sci. USA 93:15497-15502.

Lindgren, P. 1997. The role of $h r p$ genes during plant-bacterial interactions. Annu. Rev. Phytopathol. 35:129-152.

Morgan, D. G., Owen, C., Melanson, L .A., and DeRosier, D. J. 1995. Structure of the bacterial filament at $11 \AA$ resolution by electron cryomicroscopy. J. Mol. Biol. 249:88-110.

Mudgett, M. B., and Staskawicz, B. J. 1998. Protein signaling via type III secretion pathways in phytopathogenic bacteria. Curr. Opin. Microbiol. 1:109-114.

Newman, E. I. 1976. Water relations. Page 157-196 in: Plant Structure, Function and Adaptation. M. A. Hall, ed. Macmillan, London.

Perino, C., Gaudriault, S., Vian, B., and Barny, M. A. 1999.Visualization of harpin secretion in planta during infection of apple seedlings by Erwinia amylovora. Cell Microbiol. 1:131-142.

Preston, G., Huang, H.-C., He, S. Y., and Collmer, A. 1995. The HrpZ proteins of Pseudomonas syringae pvs. syringae, glycinea, and tomato are encoded by an operon containing Yersinia ysc homologs and elicit the hypersensitive response in tomato but not soybean. Mol. Plant-Microbe Interact. 8:717-732.

Roine, E., Saarinen, J., Kalkkinen, N., and Romantschuk, M. 1997a. Purified HrpA of Pseudomonas syringae pv. tomato DC3000 reassembles into pili. FEBS Lett. 417:168-172.

Roine, E., Wei, W., Yuan, J., Nurmiaho-Lassila, E. L., Kalkkinen, N., Romantschuk, M., and He, S. Y. 1997b. Hrp pilus: An hrp-dependent bacterial surface appendage produced by Pseudomonas syringae pv. tomato DC3000. Proc. Natl. Acad. Sci. USA 94:3459-3464.

Rosqvist, R., Hakansson, S., Forsberg, A., and Wolf-Watz, H. 1995. Functional conservation of the secretion and translocation machinery for virulence proteins of Yersinia, Salmonellae and Shigellae. EMBO J. 14:4187-4195.

Sambrook, J., Fritsch, E. F., and Maniatis, T. 1989. Molecular Cloning: A Laboratory Manual, 2nd ed. C. Nolan, ed. Cold Spring Harbor Laboratory Press, Cold Spring Harbor, NY, U.S.A

Stein, M., Rappuoli, R., and Covacci, A. 2000. Tyrosine phosphorylation of the Helicobacter pylori CagA antigen after cag-driven host cell translocation. Proc. Natl. Acad. Sci. USA 97:1263-1268.

Stevens, C., Bennett, M. A., Athanassopoulos, E., Tsiamis, G., Taylor, J. D., and Mansfield, J. W. 1998. Sequence variations in alleles of the avirulence gene avrPphE.R2 from Pseudomonas syringae pv. phaseolicola lead to loss of recognition of the AvrPphE protein within bean cells and a gain in cultivar-specific virulence. Mol. Microbiol. 291:165-177.

Taira, S., Tuimala, J., Roine, E., Nurmiaho-Lassila, E.-L., Savilahti, H., and Romantschuk, M. 1999. Mutational analysis of the Pseudomonas syringae pv. tomato hrpA gene encoding Hrp pilus subunit. Mol. Microbiol. 34:736-744.

Tsiamis, G., Mansfield, J. W., Hockenhull, R., Jackson, R. W., Sesma, A., Athanassopoulos, E., Bennett, M., Stevens, C. Vivian, A., Taylor, J. D., and Murillo, J. 2000. Cultivar-specific avirulence and virulence functions assigned to avrPphF in Pseudomonas syringae pv. phaseolicola, the cause of bean halo-blight disease. EMBO J. 13:3204-3214.

Van Gijsegem, F. 1997. In planta regulation of phytopathogenic bacteria virulence genes: Relevance of plant-derived signals. Eur. J. Plant Pathol. 103:291-301.

Van Gijsegem, F., Vasse, J., Camus, J.-C., Marenda, M., and Boucher, C. 2000. Ralstonia solanacearum produces Hrp-dependent pili that are required for PopA secretion but not for attachment of bacteria to plant cells. Mol. Microbiol. 36:249-260.

Von Gabain, A., Belasco, J. G., Schottel, J. L., Chang, A. C., and Cohen, S. N. 1983. Decay of mRNA in Escherichia coli: Investigation of the fate of specific segments of transcripts. Proc. Natl. Acad. Sci. USA 80:653-657.

Wei, W., Plovanich-Jones, A., Deng, W.-L., Jin, Q.-L., Collmer, A., Huang, H.-C., and He, S. Y. 2000. The gene coding for the Hrp pilus structural protein is required for type III secretion of Hrp and Avr proteins in Pseudomonas syringae pv. tomato. Proc. Natl. Acad. Sci. USA 97:2247-2252.

Whalen, M. C., Innes, R. W., Bent, A. F., and Staskawicz, B. J. 1991. Identification of Pseudomonas syringae pathogens of Arabidopsis and a bacterial locus determining avirulence on both Arabidopsis and soybean. Plant Cell 3:49-59. 